\title{
"O mundo gira sem o Mercosul": um estudo sobre os editoriais do Jornal O Estado de S. Paulo
}

\section{Francisco Paulo Jamil Marques}

Doutor; Universidade Federal do Paraná, Curitiba, PR, Brasil

marquesjamil@gmail.com

\section{Yohanna Lara Barros Pinheiro}

Graduada; Universidade Federal do Ceará, Fortaleza, CE, Brasil yohanna.lara@gmail.com

\section{Resumo}

$O$ artigo examina um conjunto de editoriais do jornal $O$ Estado de S. Paulo a fim de compreender de que maneira o periódico se posiciona discursivamente em relação ao Mercosul. Organiza-se o estudo da opinião da empresa jornalística a partir de três aspectos: o contexto político recente do bloco; o desempenho de seus agentes diplomáticos; as vantagens e desvantagens políticas e econômicas que a integração teria trazido para o Brasil. A hipótese é a seguinte: Por defender em sua carta de princípios editoriais a ideia de livre mercado, OESP cultiva uma imagem negativa do Mercosul. A seleção do corpus levou em conta 16 textos publicados entre janeiro e junho de 2013. Por meio da Análise do Discurso, foram identificadas cinco principais Formações Discursivas na amostra: (1) o que o jornal denomina de "amarras" do Mercosul; (2) uma alegada incompetência ou passividade do governo brasileiro; (3) o caráter protecionista da Argentina; (4) o perfil "antidemocrático" da Venezuela diagnosticado pela publicação em tela; e (5) a suspensão do Paraguai do bloco como um "golpe". Conclui-se que a opinião da empresa jornalística tende a desqualificar o bloco, destacando a concepção de que o Mercosul seria uma estratégia econômica fracassada e que traria consideráveis prejuízos ao Brasil.

\section{Palavras-chave}

Jornalismo. Editorial. Política internacional. Mercosul. Opinião. 


\section{Introdução}

Parte relevante da literatura na área de Política Internacional tem elencado os desafios que o Mercado Comum do Sul (Mercosul) enfrenta, tais como disputas internas, ausência de sólidas instituições de gerenciamento de conflitos e incompatibilidade monetária e cambial (SILVA; JOHNSON; ARCE, 2013). Embora essas e outras dificuldades ainda impliquem um longo caminho a ser percorrido para que o bloco se consolide em definitivo, o Mercosul ainda guarda para si um papel relevante nas relações regionais (FOLHA ONLINE, 2001).

Apesar disso, questões que envolvem Política Externa não costumam ser pauta frequente na imprensa nacional. Ao contrário do que ocorre, por exemplo, nos Estados Unidos, onde os principais jornais, assim como candidatos em épocas de eleição, enfatizam os meios e modos mais eficazes de inserção daquele país no mundo (ENTMAN, 2004), o entendimento compartilhado pelos cidadãos brasileiros acerca de nossas vitórias e fracassos em transações comerciais, missões humanitárias e cooperações de natureza militar, acaba sendo visto como algo secundário. Justamente por isso, a abordagem de tais temas acaba, muitas vezes, sendo deixada sob responsabilidade de agências internacionais de notícias. Por contarem com correspondentes em diferentes partes do mundo, agências como Reuters, Associated Press, France-Presse, dentre outras, oferecem a empresas jornalísticas de pequeno ou grande porte informações que, dificilmente, seriam obtidas sem um alto investimento financeiro.

O que interessa a esta pesquisa, contudo, não são as notícias alocadas na seção de "Internacional" oferecidas pelos grandes jornais brasileiros, apontados na literatura como quality papers (CHAGAS, 2014). 0 objetivo do artigo é compreender de que maneira o jornal O Estado de S. Paulo (OESP) se posiciona editorialmente sobre o Mercosul. Em vez de se debruçar analiticamente sobre o conteúdo noticioso - como fizeram Silveira (2005) ou Steinberger (2005a) -, a intenção é identificar os posicionamentos institucionais do jornal no que se refere à situação do bloco econômico, ao desempenho dos governos e agentes diplomáticos por ele responsáveis e às alegadas vantagens e desvantagens políticas e econômicas testemunhadas ao longo do processo de integração. Tal procedimento se mostra pertinente ao permitir identificar, por exemplo, o discurso como uma prática ideológica da qual o Jornalismo se mostra um dos agentes mais relevantes.

Para isso, foram examinados os editoriais publicados em OESP entre janeiro e junho de 2013, um período influenciado, por exemplo, por acontecimentos como a suspensão do 
Paraguai do Mercosul, a consequente entrada da Venezuela no bloco e a morte de Hugo Chávez. A hipótese fundamental é a de que a ideia de livre mercado editorialmente defendida por OESP em sua carta de princípios o faz cultivar uma imagem negativa do Mercosul.

0 artigo se encontra dividido em três tópicos. 0 primeiro traz, de forma breve, explanações teóricas e históricas a respeito do Mercosul. Em seguida, são debatidas as particularidades do Jornalismo opinativo e de como ele reivindica a condição de orientador da audiência. Na última parte, são estudados, por meio da Análise do Discurso, 16 editoriais do jornal $O$ Estado de $S$. Paulo no qual o bloco econômico selecionado para estudo é o foco principal.

Antes de prosseguir com a análise, pede-se licença para justificar a relevância da investigação em tela. Mesmo que o papel da imprensa no compartilhamento de notícias que tratam das Relações Internacionais venha sendo explorado na literatura já há algumas décadas (GALTUNG; RUGE, 1965), poucos trabalhos brasileiros se preocupam em examinar a forma pela qual os jornais cobrem acontecimentos que envolvem negociações políticas e econômicas entre diferentes países ${ }^{1}$. Tal carência de pesquisas pode ser explicada por razões diversas, a exemplo das poucas oportunidades que o público nacional tem para discutir o papel e a inserção do Brasil no mundo ou da ausência de disciplinas específicas nos cursos de Comunicação espalhados pelo País².

Ressalte-se, porém, que mais raras ainda são as contribuições que analisam, especificamente, o texto editorial e sua condição de gênero opinativo voltado a "orientar" o leitor acerca das posições que as empresas consideram pertinentes. É essa demanda que o argumento aqui delineado procura contemplar.

\section{Mercosul: trajetória política e histórica do Bloco}

Com o fim da Guerra Fria e da polarização do mundo em modelos políticos e econômicos liderados por Estados Unidos e União Soviética, fortaleceram-se blocos regionais dedicados a buscar maneiras alternativas de integração. De acordo com Celli Junior (2006), a supressão do modelo planificado de economia e o aprofundamento do processo de liberalização das transações internacionais acabaram por fortalecer a expansão

\footnotetext{
${ }^{1}$ Deve-se considerar a contribuição de autores como Campos (2010) e Soares (2004).

2 Apenas mais recentemente as Diretrizes Curriculares Nacionais para o curso de Graduação em Jornalismo mencionaram, ainda que de forma genérica, a necessidade de explorar as Relações Internacionais. Ver Brasil (2013).
} 
do mercado via livre-comércio (ALMEIDA, 2002; SOUTO MAIOR, 2006). A opção do Brasil por formar um bloco com os vizinhos procurou, assim, dar respostas à realidade emergente no final do século XX.

Em 26 de março de 1991, Argentina, Brasil, Paraguai e Uruguai assinaram o Tratado de Assunção, formando o Mercosul. 0 objetivo era promover a integração dos quatro países através do estabelecimento de uma Tarifa Externa Comum (TEC), da adoção de uma política comercial compartilhada, da coordenação de políticas macroeconômicas e setoriais, e da harmonização de legislações nas áreas pertinentes (BRASIL, 2014a).

O bloco é formado por duas categorias de países: os membros plenos e os estados associados. Além dos quatro países fundadores (Brasil, Argentina, Paraguai e Uruguai), a Venezuela também possui título de membro pleno desde agosto de 2012.

Com mais de duas décadas de existência e já tendo colhido alguns êxitos, o bloco ainda enfrenta desafios: não obstante a proximidade geográfica e os traços históricos comuns, disputas internas continuam a se mostrar proeminentes (SILVA; JOHNSON; ARCE, 2013). A título de ilustração, menciona-se que diplomatas e empresários de cada lado medem forças em setores a exemplo do automotivo, de carnes e de têxteis (BERNAL-MEZA, 2008; VIGEVANI; MARIANO; MENDES, 2002).

É verdade que outras opções de associação foram cogitadas, principalmente, no fim dos anos 1990. A proposta norte-americana de criação da ALCA (Área de Livre-Comércio das Américas), contudo, esbarrou na heterogeneidade econômica, geográfica, social e cultural que caracteriza os países do continente (BATISTA JR., 2008). Isso fez com que alguns estados procurassem alternativas, enquanto de um lado, Estados Unidos e Chile optaram por um acordo bilateral em 2004, de outro lado, Brasil, Argentina, Uruguai e Paraguai continuaram a investir na conformação de um bloco comum.

Desde 2012, as relações no âmbito do Mercosul foram marcadas por acontecimentos que, conforme atestam Silva, Johnson e Arce (2013), alternariam momentos de otimismo e de esgotamento. Três fatos, retomados a seguir, merecem destaque.

\subsection{A suspensão do Paraguai}

Fernando Lugo disputou as eleições presidenciais paraguaias em abril de 2008, candidatando-se pela Alianza Patriótica para el Cambio (APC) (FOLETTO, 2011). Elegeu-se por meio de uma coligação com os liberais. No entanto, segundo Camargo, Gabiatti e Mello (2012, p. 158), o mandato de Lugo "[...] foi engessado pela forte oposição dos partidos da 
direita paraguaia [...]". Escândalos políticos, a exemplo de denúncias relativas a seus relacionamentos amorosos, trouxeram mais instabilidade política e acabaram abalando a imagem pública do mandatário.

Foi justamente no governo Lugo que surgiu, no Paraguai, um braço do movimento social dos "sem-terra", chamado de carperos (CAMARGO; GABIATTI; MELLO, 2012). Segundo Schembida (2012), no dia 15 de junho de 2012, onze camponeses e seis militares foram mortos em um confronto entre carperos e forças policiais durante a desocupação de uma fazenda. Menos de uma semana após o incidente, o Senado paraguaio assumiu o papel de tribunal político e deflagrou o procedimento de impeachment contra Lugo (SCHEMBIDA, 2012). Diante do ocorrido, a Cúpula do Mercosul, decidiu em Mendoza, na Argentina, no dia 29 de junho de 2012, por condenar a ruptura da ordem democrática ocorrida naquele país e afastar o Paraguai temporariamente das decisões do bloco (GEHRE, 2012).

O processo possibilitou o ingresso da Venezuela no Mercosul - que, até então, dependia apenas da aprovação do Paraguai. 0 governo paraguaio se opôs à adesão da Venezuela ao bloco e chegou a ameaçar não voltar para o Mercosul após a realização de novas eleições (PALACIOS; VILLAVERDE, 2013). Na reunião da cúpula realizada em Montevidéu, em julho de 2013, os países membros do bloco revogaram a decisão que suspendia o Paraguai das decisões do bloco, devolvendo ao país plenos direitos de participação nos órgãos do Mercosul e nas deliberações (RITTNER, 2013).

\subsection{A entrada da Venezuela}

A imagem recente da Venezuela é indissociável de Hugo Chávez, líder que permaneceu no poder de 1999 até sua morte, em 2013. 0 governo Chavista, de acordo com Bijos e Cavalcante (2013, p. 10), foi “[...] um misto de democracia controlada com a mão forte da tirania, combinando eleições periódicas com uma cada vez maior concentração do poder em suas mãos [...]". Os mesmos autores afirmam que Chávez adotou medidas polêmicas, a exemplo da intervenção em meios de comunicação não-estatais. Conforme explicam Bijos e Cavalcante (2013), o Chavismo foi um entrave complexo à integração regional, sobretudo por conta da cláusula democrática ${ }^{3}$ do Mercosul.

Na avaliação de Teruchkin (2006, p. 48), a entrada de tal país no Mercosul significou “[...] um importante passo para o aprofundamento da integração econômica da América

\footnotetext{
3 De acordo com o Artigo $1^{\text {o }}$ do Protocolo de Ushuaia (1998), “[...] a plena vigência das instituições democráticas é condição essencial para o desenvolvimento dos processos de integração entre os Estados Partes do presente Protocolo [...]".
} 
Latina [...]". Já Sturaro e Frota (2012) defendem que a principal implicação ao se admitir a Venezuela foi o enfraquecimento do bloco, uma vez que o fato de o regime venezuelano não ser plenamente democrático tornaria a decisão, na opinião dos autores, inconsistente.

\section{3 A questão argentina}

Resistências à abertura econômica e ao aprofundamento da liberalização do comércio regional são características que, de acordo com Macadar (2009), predominam atualmente no "regionalismo pós-liberal" da América do Sul. Segundo a autora, tem se acentuado a cautela ao se realizar qualquer tipo de concessão no âmbito econômico. Em relação à Argentina, Macadar (2009) sugere que o desinteresse desse país pela agenda de aprofundamento da união aduaneira do Mercosul é visível - a título de ilustração, ressaltese que a Argentina se opôs à redução de tarifas para produtos industriais na Rodada Doha (RODRIGUES; PAULA, 2008).

Por um lado, setores ligados ao Itamaraty e à Presidência brasileira (então ocupada pelo Partido dos Trabalhadores) defendem o exercício da tolerância em relação aos países do Cone Sul: o Brasil "[...] deve absorver alguns custos devido a seu papel de liderança regional [...]" (MACADAR, 2009, p. 9). Entretanto, a autora aponta que outros setores do governo de Lula e de Dilma defendem uma reação mais enérgica às medidas protecionistas implementadas pela Argentina, denunciando o parceiro de bloco à OMC nas ocasiões em que os prejuízos se avolumem.

Exposto o panorama das tensões que marcaram o Mercosul nos últimos anos, acredita-se ter oferecido, ainda que de maneira introdutória, a base teórico-histórica que contribuirá para a análise dos editoriais selecionados como objeto de estudo desta pesquisa. No próximo tópico, serão discutidas as características e as repercussões do Jornalismo opinativo, bem como a trajetória do jornal $O$ Estado de S. Paulo.

\section{Jornalismo opinativo e opinião pública}

Luiz Beltrão (1980) defende que cabe ao jornalista a função de "pregoeiro da opinião", para que ela esteja ao alcance de todos. De acordo com o autor, o papel moral e social do profissional do Jornalismo vai, portanto, além da finalidade puramente informativa. Não por acaso, o Jornalismo guarda o traço da opinião desde a sua gênese (MELO, 2003; PENA, 2010; MARQUES; MIOLA; SIEBRA, 2014). De acordo com Sousa (2008), 
ao se modernizar e buscar legitimidade, o Jornalismo passou a separar a opinião de um lado, da informação, de outro, chegando-se ao modelo comercial hoje conhecido. Conforme Traquina (2005), a expansão dos jornais no século XIX fez com que a atividade ganhasse um novo paradigma, caracterizado pela busca do ideal de verdade, independência, objetividade e pela noção de serviço público (dentre os autores que debatem de forma aprofundada a relação entre opinião e objetividade no Jornalismo contemporâneo estão Cook (2005), Schudson (2008) e Tuchman (1972), Albuquerque (2000) e Mont'Alverne e Marques (2015). É por isso que os jornais adotam uma abordagem diferenciada entre as páginas que trazem notícias e as que carregam os pontos de vista de articulistas, colunistas ou da própria instituição.

Mesmo ciente de tal distinção, autores a exemplo de Melo (2003) caracterizam o editorial como um "espaço de contradições" justamente por veicular o posicionamento oficial da empresa. Isto é, constitui-se um espaço legítimo para a veiculação de opiniões, mas gera desconfiança por parte do leitor quanto à viabilidade de uma cobertura equilibrada na seção noticiosa. Para o autor, “[...] a opinião contida no editorial constitui um indicador que pretende orientar a opinião pública [...]" (MELO, 2003, p. 104).

Mostra-se relevante, assim, a análise do editorial enquanto categoria do Jornalismo opinativo, uma vez que é a partir dele que se pode compreender com maior facilidade a imagem que determinada empresa constrói de governantes ou de instituições.

Se o discurso é construído ao longo da prática discursiva, é preciso ter conhecimento sobre o contexto midiático, isto é, acerca da posição que determinado periódico ocupa no campo do Jornalismo (GOMES, 2004). O Estado de S. Paulo é um dos principais jornais do País ${ }^{4}$, tendo sido fundado em 4 de janeiro de 1875, ainda na época do período imperial brasileiro, com o nome A Província de S. Paulo. Durante sua trajetória, o periódico se posicionou politicamente diversas vezes. Em 1909, por exemplo, apoiou a candidatura de Ruy Barbosa à Presidência - o que levou Júlio Mesquita, então proprietário da empresa, à prisão (MAYRINK, 2011). Em 1930, o Estadão defendeu a candidatura de Getúlio Vargas (LISBOA, 2012). No entanto, no âmbito do golpe que estabeleceu o Estado Novo (19371945), Júlio de Mesquita Filho, herdeiro da empresa, foi preso e expatriado. Em 1964, o Estadão declarou-se favorável ao levante militar que depôs João Goulart. Com a redemocratização do País, o jornal tomou partido nas eleições presidenciais de 2010,

\footnotetext{
${ }^{4}$ De acordo com a Associação Nacional de Jornais (2014), OESP foi o sétimo periódico de maior média de circulação no Brasil em 2014, com a tiragem média de 237.901 exemplares impressos e digitais.
} 
quando, a uma semana do pleito, em 25 de setembro, publicou um editorial no qual declarava apoio ao candidato José Serra (LISBOA, 2012). Verifica-se, então, a importância que a empresa confere a seus posicionamentos políticos, o que reforça a justificativa por investigar seus editoriais.

A seção de opinião do jornal OESP é identificada pelo título "Notas e informações", seção fixa nas páginas 2 e 3 do primeiro caderno. Todos os dias, a editoria é composta por dois artigos de opinião assinados, três editoriais, um quadro para o fórum de leitores e outro para informações institucionais. Outro editorial é publicado de terça a domingo, no caderno Economia \& Negócios.

O Grupo Estado (2016) esclarece quais são seus princípios editoriais no Código de Conduta e Ética. As diretrizes que orientam as empresas (e, consequentemente, os editoriais) são:

1) 0 Grupo Estado defende o sistema democrático de governo, a livre iniciativa, a economia de mercado e um Estado comprometido com um país economicamente forte e socialmente justo; 2) Sente-se responsável pela promoção do desenvolvimento humano, político, econômico, social e cultural do Brasil, dando coesão à sociedade civil; [...] 4) [...] defende editorialmente os direitos e as liberdades individuais, o pluralismo democrático e a identidade sóciocultural do Brasil e de São Paulo; [...] 6) [...] defenderá os cidadãos das agressões de qualquer forma de poder e estimulará a livre iniciativa em todos os âmbitos da atividade humana; [...] 8) [...] Recusam-se, no entanto, a veicular teses que neguem a liberdade, atentem contra a dignidade da pessoa humana ou agridam os princípios da ética informativa definidos neste documento (grupo estado, 2016, documento eletrônico).

Dada a relevância do periódico para a formação das visões de mundo compartilhadas por parcela significativa da sociedade brasileira, bem como por conta da firmeza com que declara seus posicionamentos nos editoriais, justifica-se a escolha pela análise das representações discursivas veiculadas em OESP. Retoma-se a hipótese de que seus princípios editoriais levam a empresa a cultivar uma imagem negativa do Mercosul, que seria visto como um entrave à livre iniciativa e ao pleno desenvolvimento da economia de mercado.

\section{Análise dos editoriais}

De modo a reunir material necessário para identificar os posicionamentos institucionais do jornal $O$ Estado de S. Paulo, escolheu-se um conjunto de textos publicados 
pelo referido periódico entre janeiro e junho de 2013. É nesse intervalo em que se verificam os desdobramentos das tensões relacionadas à suspensão do Paraguai, à entrada da Venezuela no bloco em junho de 2012 e a repercussão da morte do presidente Hugo Chávez, ocorrida em março de 2013.

Os editoriais foram coletados a partir do mecanismo de pesquisa do próprio site do Estadão (2016). A unidade de registro empregada para realizar a busca na seção específica dos editoriais foi o termo "Mercosul", tal como propõe Weber (1990) ao fazer um apanhado de sugestões sobre técnicas de coleta de dados. Dessa forma, chegou-se ao total de 16 textos selecionados para análise (Quadro 1). Por questões de limitação de espaço, destacam-se apenas os trechos que mais chamam a atenção quanto à postura discursiva do periódico.

Quadro 1 - Lista de editoriais selecionados para análise

\begin{tabular}{|c|c|c|}
\hline No & Data & Título \\
\hline E01 & $09 / 01 / 2013$ & O Brasil no jogo chavista \\
\hline E02 & $30 / 01 / 2013$ & Pobreza de ideias \\
\hline E03 & $12 / 03 / 2013$ & O mundo gira sem o Mercosul \\
\hline E04 & $19 / 03 / 2013$ & O alvo do governo Kirchner \\
\hline E05 & $04 / 04 / 2013$ & Chávez, o passarinho \\
\hline E06 & $16 / 04 / 2013$ & Atrativos do Paraguai \\
\hline E07 & $23 / 04 / 2013$ & A volta dos colorados \\
\hline E08 & $27 / 04 / 2013$ & Uma reunião vazia \\
\hline E09 & $09 / 05 / 2013$ & Em busca de legitimidade \\
\hline E10 & $09 / 05 / 2013$ & Um brasileiro na OMC \\
\hline E11 & $11 / 05 / 2013$ & Chá de cadeira em Dilma \\
\hline E12 & $29 / 05 / 2013$ & O mundo negocia sem o Brasil \\
\hline E13 & $05 / 06 / 2013$ & Má diplomacia, mau comércio \\
\hline E14 & $19 / 06 / 2013$ & Má lição para novos diplomatas \\
\hline E15 & $20 / 06 / 2013$ & Uma Fiesp bolivariana? \\
\hline E16 & $22 / 06 / 2013$ & O acordo automotivo, de novo \\
\hline
\end{tabular}

Fonte: Elaborado pelos autores.

Existem questões para as quais uma análise qualitativa se mostra mais adequada para dar respostas - por exemplo, o próprio diagnóstico acerca do posicionamento discursivo da empresa jornalística. Tendo em vista o objetivo da pesquisa, optou-se, assim, 
por utilizar os mecanismos da Análise do Discurso (AD) para sistematizar e tornar possível o exame da amostra definida.

De acordo com Capelle, Melo e Gonçalves (2003, p. 13), a AD “[...] considera que a situação está atestada no texto e busca mais a compreensão do processo produtivo do discurso [...]", ou seja, visa entender como o texto "[...] funciona diante de um determinado contexto social e histórico [...]". Para Manhães (2010), o discurso é, portanto, a "apropriação da linguagem" por um emissor, que classifica, ordena, organiza, persuade e constrói um entendimento, tornando-se, assim, sujeito da ação social.

Compreendendo o Jornalismo como "um lugar de circulação e produção de sentidos" (BENETTI, 2008), entende-se que a AD é o método apropriado para identificar as escolhas do jornalista ou da empresa no momento da elaboração do texto, o que exige compreensão dos modos de funcionamento do discurso. Segundo Benetti (2008), a corrente francesa da Análise do Discurso é "especialmente produtiva" para a identificação dos sentidos e para o mapeamento de vozes no discurso jornalístico. De acordo com a autora, o Jornalismo constrói sentidos sobre a realidade, interferindo sobre ela contínua e mutuamente, não podendo ser analisado fora do contexto histórico - justamente por isso o argumento aqui delineado teve o cuidado de apresentar as tensões recentes que marcaram o Mercosul.

Com o entendimento de que a exterioridade não apenas repercute, mas, de fato, constitui o texto e dele não pode ser separada, Benetti (2008, p. 111-112) aponta que, ao utilizar tal método, o pesquisador deve detectar a existência de duas camadas: "[...] a primeira, mais visível, é a camada discursiva; a segunda, só evidente quando aplicamos o método, é a camada ideológica [...]”. Ela explica que a análise deve partir da identificação de "formações discursivas (FDs)" no texto, que podem ser entendidas como um posicionamento (ou "sentido nuclear"), construído através de argumentos. Isto é, cada FD é formada por pequenos significados que, unidos, consolidam o "sentido nuclear" transmitido pelo texto, havendo “[...] tantas formações discursivas quantos sentidos nucleares pudermos encontrar [...]".

Em um segundo momento, Benetti (2008) pondera que a instituição jornalística constrói um movimento de paráfrase, isto é, reforça o mesmo sentido através das sequências discursivas (SDs) ao longo do(s) texto(s). Cabe ao pesquisador evidenciar tais sequências discursivas, trechos recortados do material sob análise para consolidar o "sentido nuclear" apontado no estudo, ajudando a compreender, assim, em que medida certas visões de mundo são ou não interditadas no texto. Assim, de acordo com o que o 
leitor poderá perceber, faz-se questão de indicar em cada tópico a seguir uma quantidade relevante de SDs, justamente a fim de comprovar a reiteração dos sentidos e diminuir o grau de subjetividade da analise qualitativa.

Em tempo, ressalte-se a menção a Mazière (2007), para quem, em Análise do Discurso, não se pode falar em neutralidade do investigador. A escolha de uma dentre as alternativas possíveis para a composição do corpus, por exemplo, já implicaria uma predisposição adotada no desenho da pesquisa. Uma análise prévia (com leitura e releitura das unidades de análise) realizada em parceria pelos autores revelou cinco sentidos nucleares, isto é, Formações Discursivas nos editoriais de OESP: (1) as "amarras" do Mercosul; (2) a incompetência/passividade do governo brasileiro; (3) a Argentina protecionista; (4) a Venezuela antidemocrática; e (5) a suspensão do Paraguai como "golpe". Estas foram as questões sobre as quais o jornal se posicionou mais fortemente nos editoriais que tratavam do bloco durante o período investigado.

A partir da definição das FDs, buscaram-se, no corpo dos textos, as SDs que reforçavam a ideia representada pela formação discursiva (numerando-as, a fim de facilitar a organização). Há SDs que se encaixam em mais de uma das formações identificadas. Para esses casos, optou-se por destacar o sentido julgado ser mais significativo para cada SD.

A seguir, cada Formação Discursiva é examinada em detalhes. Conforme o leitor perceberá, trechos (Sequências Discursivas) de todos os editoriais que compõem o corpus estão ilustrados ao longo da análise. Ao adotar tal procedimento, o objetivo é comprovar que existe um sentido comum compartilhado pelos editoriais, constituindo uma representação que vai além de cada unidade textual. As passagens realçadas permitem verificar as ênfases escolhidas pelos editoriais e auxiliam na consideração da hipótese de investigação apresentada anteriormente.

De modo concomitante à apresentação dos dados (e a fim de evitar uma mera descrição dos editoriais), empreende-se uma discussão mais aprofundada sobre o posicionamento discursivo do jornal, cotejando-se os achados empíricos com as perspectivas de diferentes autores sobre o papel do Jornalismo enquanto "orientador" da audiência. Também se aproveita a ocasião para criticar o posicionamento da empresa naquelas oportunidades em que os editoriais desconsideram informações relevantes para que o leitor tenha um quadro completo sobre, por exemplo, as vantagens e as desvantagens do Mercosul. 


\subsection{FD1: as "amarras" do Mercosul}

Silva, Johnson e Arce (2013) afirmam que o Mercosul, ao longo de pouco mais de duas décadas de existência, foi marcado pela "oscilação entre o otimismo e o esgotamento". Levando em conta esse cenário, procurou-se delimitar o posicionamento do Estadão sobre as alegadas dificuldades que o bloco enfrenta. Os trechos dos editoriais que mais se dedicam a esse aspecto estão disponíveis abaixo.

Quadro 2 - Sequências discursivas relacionadas à ideia de que o Mercosul seria uma "amarra" para o desenvolvimento

\begin{tabular}{|c|c|}
\hline Sequência discursiva & Editorial \\
\hline $\begin{array}{l}\text { SD01: "juízo continua sendo um insumo escasso na América Latina e } \\
\text { especialmente no Mercosul." }\end{array}$ & $\begin{array}{l}\text { E02: Pobreza de } \\
\text { ideias }\end{array}$ \\
\hline $\begin{array}{l}\text { SD02: "Até agora, o Mercosul negociou poucos acordos de livre } \\
\text { comércio, sempre com parceiros em desenvolvimento e, em alguns } \\
\text { casos, sem relevância econômica para o Brasil." }\end{array}$ & $\begin{array}{l}\text { E03: O mundo gira } \\
\text { sem o Mercosul }\end{array}$ \\
\hline $\begin{array}{l}\text { SD03: "Brasil e Argentina são os principais integrantes do Mercosul, o } \\
\text { bloco do Cone Sul que, teoricamente, é uma união aduaneira, na qual } \\
\text { é livre a circulação de bens e serviços." }\end{array}$ & $\begin{array}{l}\text { E04: } 0 \text { alvo do } \\
\text { governo Kirchner }\end{array}$ \\
\hline $\begin{array}{l}\text { SD04: "além de crescentemente irrelevante, o Mercosul agora se } \\
\text { presta ao papel de avalista de um regime que pretende ser legítimo } \\
\text { na marra [Venezuela]." }\end{array}$ & $\begin{array}{l}\text { E09: Em busca de } \\
\text { legitimidade }\end{array}$ \\
\hline $\begin{array}{l}\text { SD05: "Enquanto outros países se movem, o Brasil continua preso a } \\
\text { um bloco emperrado pelo protecionismo interno e incapaz de } \\
\text { concluir acordos comerciais relevantes." }\end{array}$ & $\begin{array}{l}\text { E12: } 0 \text { mundo } \\
\text { negocia sem o } \\
\text { Brasil }\end{array}$ \\
\hline $\begin{array}{l}\text { SD06: "A mesma fantasia explica a insistência do governo em } \\
\text { manter o País amarrado a uma união aduaneira fracassada, o } \\
\text { Mercosul, um bloco incapaz de funcionar como simples área de } \\
\text { livre comércio." }\end{array}$ & $\begin{array}{l}\text { E14: Má lição para } \\
\text { novos diplomatas }\end{array}$ \\
\hline $\begin{array}{l}\text { SD07: “O Mercosul é hoje muito mais um empecilho do que uma } \\
\text { estrutura capaz de ter peso nas decisões internacionais, disse na } \\
\text { terça-feira o presidente da Confederação Nacional da Indústria, } \\
\text { Robson Braga de Andrade." }\end{array}$ & \multirow[b]{2}{*}{$\begin{array}{l}\text { E15: Uma Fiesp } \\
\text { bolivariana? }\end{array}$} \\
\hline $\begin{array}{l}\text { SD08: "Essas amarras limitam, sim, as possibilidades de acordos } \\
\text { internacionais mais variados e comercialmente mais vantajosos. As } \\
\text { limitações teriam sido mais evidentes se o governo brasileiro tivesse } \\
\text { buscado esses acordos mais ativamente, em vez de se restringir a } \\
\text { uma política terceiro-mundista." }\end{array}$ & \\
\hline $\begin{array}{l}\text { SD09: "Sua prematura transformação em união aduaneira, em } \\
\text { 1995, tornou ainda mais injustificável o acordo automotivo. Mas, } \\
\text { por pressão dos fabricantes argentinos de veículos, ele vigora desde } \\
\text { 2000, com alterações pouco significativas feitas em suas } \\
\text { sucessivas renovações..." }\end{array}$ & $\begin{array}{l}\text { E16: } 0 \text { acordo } \\
\text { automotivo, de } \\
\text { novo }\end{array}$ \\
\hline
\end{tabular}

Fonte: Elaborado pelos autores. 
No conjunto de SDs destacadas, percebe-se que os editoriais são enfáticos quanto à posição do jornal acerca do Mercosul. Caracterizando-o como "incapaz", "união aduaneira fracassada" e "empecilho", os textos exprimem uma profunda frustração com os rumos tomados pelo bloco, que o jornal afirma ser "emperrado pelo protecionismo interno e incapaz de concluir acordos comerciais relevantes" (SD05).

Na SD01, ao afirmar que falta "juízo" na América Latina, o jornal aponta o que considera falta de discernimento aos representantes políticos da região. Segundo argumentos presentes no editorial, as constantes medidas protecionistas tomadas por países-membros do bloco seriam um entrave para as negociações econômicas.

Para o jornal, a culpa de tal cenário, como se pode extrair a partir da SD06, é da política externa brasileira, motivada pela "insistência" do país em permanecer no bloco. Além disso, na SD09, são abertamente criticadas as estratégias de relações externas do governo, ao se cobrar uma posição mais ativa da chancelaria brasileira em busca de acordos econômicos que não se restrinjam a uma "política terceiro-mundista", como OESP define.

0 único momento em que o bloco não é percebido de forma negativa é no Editorial 2 (E02), quando se afirma que, na negociação da Comunidade de Estados Latino-Americanos e Caribenhos (CELAC) com a União Europeia (UE), deveria ter sido priorizado um acordo dos europeus com o Mercosul, que seria um bloco "razoavelmente estruturado, pelo menos em termos formais".

\subsection{FD2: a incompetência/passividade do governo brasileiro}

Nos editoriais que fazem parte da amostra, o jornal OESP não poupa críticas ao governo comandado por Dilma Rousseff (PT). Na tabela abaixo, estão identificadas as SDs em que são feitas referências a representantes, ações ou estratégias do governo brasileiro. Verifica-se que, em diferentes oportunidades, um mesmo editorial traz passagens com críticas diversas ao comportamento político dos representantes do País. 
Quadro 3 - Sequências discursivas relacionadas à crítica sobre a atuação do governo brasileiro

\begin{tabular}{|c|c|}
\hline Sequência discursiva & Editorial \\
\hline $\begin{array}{l}\text { SD10: “A impropriedade do assessor internacional do Planalto está } \\
\text { muito menos no seu ensaio de exegese da Constituição de outro país do } \\
\text { que em ele não ter se lembrado da famosa interpelação do rei espanhol } \\
\text { Juan Carlos ao próprio Chávez: ¿ ¿Por que no te callas?”' }\end{array}$ & $\begin{array}{l}\text { E01: O Brasil } \\
\text { no jogo } \\
\text { chavista }\end{array}$ \\
\hline $\begin{array}{l}\text { SD11: “A nova esperteza argentina é mais uma comprovação do erro } \\
\text { cometido pelo governo petista, há dez anos, quando optou por um } \\
\text { regionalismo ingênuo inspirado em bandeiras terceiro-mundistas." }\end{array}$ & $\begin{array}{l}\text { E03: O mundo } \\
\text { gira sem o } \\
\text { MERCOSUL }\end{array}$ \\
\hline $\begin{array}{l}\text { SD12: “Crescentemente atolado no difícil relacionamento com a } \\
\text { Argentina, o governo brasileiro tem espaço cada vez menor para se } \\
\text { ajustar às novas condições do mercado internacional." }\end{array}$ & \multirow{2}{*}{$\begin{array}{l}\text { E03: } 0 \text { mundo } \\
\text { gira sem o } \\
\text { MERCOSUL }\end{array}$} \\
\hline $\begin{array}{l}\text { SD13: “Enquanto isso, acordos bilaterais e inter-regionais multiplicam-se } \\
\text { em todo o mundo, sem a participação do Brasil. Ou seja, o Brasil está cada } \\
\text { vez mais fora do jogo relevante para o comércio internacional." }\end{array}$ & \\
\hline $\begin{array}{l}\text { SD14: “Os números da balança comercial entre os dois países não deixam } \\
\text { dúvidas de que a condescendência com que o governo Dilma reage às } \\
\text { restrições comerciais da Argentina estimula a ação dos funcionários do } \\
\text { governo Kirchner notoriamente contrários à entrada de produtos } \\
\text { brasileiros em seu país." }\end{array}$ & \multirow{2}{*}{$\begin{array}{l}\text { E04: } 0 \text { alvo } \\
\text { do governo } \\
\text { Kirchner }\end{array}$} \\
\hline $\begin{array}{l}\text { SD15: “Se o governo Dilma não mudar sua atitude em relação à } \\
\text { Argentina, o governo Kirchner se sentirá ainda mais livre para } \\
\text { prejudicar o Brasil." }\end{array}$ & \\
\hline $\begin{array}{l}\text { SD16: "Dos reais interesses dos países que representam, e que } \\
\text { motivaram o encontro [entre Rousseff e Kirchner], porém, pouco haverá } \\
\text { de que se lembrar." }\end{array}$ & \multirow{2}{*}{$\begin{array}{l}\text { E08: Uma } \\
\text { reunião vazia }\end{array}$} \\
\hline $\begin{array}{l}\text { SD17: “As frequentes medidas de restrição impostas pelo governo } \\
\text { Kirchner à entrada de produtos brasileiros no mercado argentino [...] } \\
\text { estão sendo toleradas pelo governo Dilma - mesmo que essas ações } \\
\text { desvirtuem o estatuto do Mercosul...” }\end{array}$ & \\
\hline $\begin{array}{l}\text { SD18: "Ele [Roberto Azevêdo] tem sido um raro exemplo de seriedade e } \\
\text { competência nos postos mais importantes da diplomacia brasileira, } \\
\text { dominada há anos por um terceiro-mundismo rastaquera. } \\
\text { Igualmente rara é essa vitória de uma diplomacia incapaz, há uns dez } \\
\text { anos, de conseguir apoio até entre os vizinhos pouco influentes." }\end{array}$ & \multirow{2}{*}{$\begin{array}{l}\text { E10: Um } \\
\text { brasileiro na } \\
\text { OMC }\end{array}$} \\
\hline $\begin{array}{l}\text { SD19: “Foi certamente decisivo o apoio da China e da Rússia. Mas esses } \\
\text { dois países têm objetivos próprios bem definidos, relações comerciais } \\
\text { mais intensas com o mundo rico do que com o Brasil e nenhum } \\
\text { compromisso terceiro-mundista. Atribuir esse resultado a algum acerto } \\
\text { da geopolítica petista só pode ser má-fé ou ingenuidade. }\end{array}$ & \\
\hline $\begin{array}{l}\text { SD20: “A presidente do Brasil é Dilma Rousseff, mas isso parece ser } \\
\text { apenas um detalhe. Na fabulação bolivariana, ela não passa de uma } \\
\text { nota de rodapé ante os 'gigantes' Luiz Inácio Lula da Silva, Hugo Chávez } \\
\text { e Néstor Kirchner. }\end{array}$ & \multirow[t]{2}{*}{$\begin{array}{l}\text { E11: Chá de } \\
\text { cadeira em } \\
\text { Dilma }\end{array}$} \\
\hline $\begin{array}{l}\text { SD21: “No culto à personalidade de Chávez e Lula, Dilma é cada vez } \\
\text { mais apenas uma coadjuvante." }\end{array}$ & \\
\hline
\end{tabular}


SD22: "Nos últimos dez anos, o governo brasileiro agiu como se a busca de mais acordos com o mundo rico fosse mais arriscada que vantajosa e, é claro, um erro geopolítico e um pecado ideológico."

SD23: "Os quatro países da Aliança do Pacífico têm crescido mais que o Brasil, com inflação menor, e têm multiplicado acordos comerciais com E12: 0 mundo negocia sem 0 países desenvolvidos e em desenvolvimento, sem se prender a discriminações entre economias do Norte e do Sul."

SD24: "O terceiro-mundismo do governo petista deu prioridade às relações com países emergentes e até em estágios iniciais de desenvolvimento. A negociação de um acordo de livre comércio entre Mercosul e União Europeia logo empacou... [...] A maior parte dos erros é atribuível à política petista."

SD25: "A presidente Dilma Rousseff celebrou dez anos de incompetência e equívocos diplomáticos em seu discurso à nova turma formada pelo Instituto Rio Branco. Seu pronunciamento, na terça-feira, se harmonizou perfeitamente com os erros de avaliação e as fantasias geopolíticas do terceiro-mundismo petista.

SD26: "a incompetência governamental, no Brasil, prejudica também o poder de competição das empresas. A combinação de erros diplomáticos e de política econômica interna tem resultado igualmente na perda de participação nos mercados vizinhos."

SD27: "Ainda segundo o estudo, o Brasil, com seu peso, 'tem plenas condições de liderar o Mercosul' em negociações com países ou regiões de fora do bloco. Se tem essas condições, por que deixou de usá-las até hoje?"

SD28: "O regime de liberdade comercial, aliás, deveria estar em vigor desde a criação do Mercosul, há 22 anos, mas, por pressão argentina generosamente tolerada pelo governo brasileiro, vem sendo seguidamente adiado."

SD29: "Com a provável renovação desse acordo injustificável numa união aduaneira, o Brasil se aprofundará num atoleiro comercial que o impede de abrir mercados muito mais promissores por meio de acordos bilaterais, que são desprezados pelo governo do PT." Fonte: Elaborado pelos autores.

E14: Má lição para novos diplomatas

E13: Má

diplomacia, mau comércio
E15: Uma

Fiesp bolivariana?

E16: 0 acordo automotivo, de novo

Como se pode perceber pela quantidade de SDs que reforçam o sentido expresso pela FD em questão, o jornal opõe-se fortemente às ações governamentais brasileiras no âmbito do Mercosul. Em várias sequências, as estratégias nacionais de comércio exterior são criticadas e desqualificadas diretamente.

A gestão e o partido petistas são frequentemente associados ao que o jornal chama de "terceiro-mundismo" (SD11, SD18, SD19, SD24, SD25), o que implicaria, na perspectiva da publicação, rebaixar o Brasil à condição do subdesenvolvimento. Na SD11, por exemplo, o editorial afirma que o governo petista errou ao optar por um "regionalismo ingênuo 
inspirado em bandeiras terceiro-mundistas". Pode-se inferir desse trecho que, para o jornal, a integração entre os países da América Latina corresponde a um regionalismo infrutífero.

Um dos principais argumentos utilizados para sustentar a acusação de incompetência do governo brasileiro é a passividade com que, segundo o jornal, ele aceita as medidas protecionistas da Argentina (SD12, SD14, SD15, SD17, SD28 e SD29), destacandose o caráter "passivo" do Brasil nas negociações.

Nesse cenário, o Brasil é retratado como se estivesse de fora "do jogo relevante para o comércio internacional" (SD13), isto é, com "espaço cada vez menor para se ajustar às novas condições do mercado" (SD12). Dessa forma, pode-se entender que, para o jornal, o culpado pela difícil posição do Brasil ante o comércio internacional é o governo. A posição clara do periódico, nesse caso, ilustra a ideia de Pêcheux (1980, p. 182) sobre como os interesses se revelam discursivamente: "[...] no se puede pretender hablar de discursos políticos sin tomar posición simultáneamente, en la lucha de clases, ya que esta toma de posición en realidad determina el modo de concebir las formas materiales concretas bajo las cuales las ideas entran en lucha en la historia [...]".

\subsection{FD3: a Argentina protecionista}

As medidas protecionistas da Argentina são amplamente criticadas por OESP, o que motivou o estudo de uma Formação Discursiva específica. Perceba-se que, no caso, a posição do jornal deixa em segundo plano a atuação do governo brasileiro para se dedicar, especificamente, às ações do governo do país vizinho.

Quadro 4 - Sequências discursivas relacionadas à critica sobre o papel da Argentina no Mercosul

\begin{tabular}{|l|l|}
\hline \multicolumn{1}{|c|}{ Sequência discursiva } & \multicolumn{1}{|c|}{ Editorial } \\
\hline $\begin{array}{l}\text { SD30: “Governo e empresários argentinos, cada vez mais } \\
\text { protecionistas, têm dificultado qualquer compromisso de } \\
\text { liberalização de mercados. Tiveram papel significativo no } \\
\text { abandono da Rodada Doha, entravaram qualquer acerto com os } \\
\text { europeus e criam obstáculos ao funcionamento do próprio } \\
\text { Mercosul." }\end{array}$ & $\begin{array}{l}\text { E02: Pobreza de } \\
\text { ideias }\end{array}$ \\
\hline $\begin{array}{l}\text { SD31: “O governo argentino pretende arrancar mais vantagens do } \\
\text { Brasil, em mais uma revisão do acordo automotivo assinado em 2000 } \\
\text { para acabar em 2005...” }\end{array}$ & $\begin{array}{l}\text { E03: O mundo gira } \\
\text { sem o Mercosul }\end{array}$ \\
\hline SD32: “Comércio aberto está fora da agenda da Casa Rosada." & \\
\hline
\end{tabular}


SD33: "A redução de 73\% registrada em 2012 no saldo do Brasil no comércio com a Argentina [...] não deixa dúvidas de que a política protecionista cada vez mais agressiva do governo da presidente Cristina Kirchner tem um alvo específico."

SD34: “Desde meados da década passada, no entanto, a Argentina vem restringindo a entrada de produtos estrangeiros, mesmo os originários de outros países do Mercosul."

E04: 0 alvo do governo Kirchner

SD35: "As presidentes dos dois países [Brasil e Argentina] deveriam discutir, entre outras, a questão da deterioração do comércio bilateral por causa do crescente protecionismo argentino."

Fonte: Elaborado pelos autores.

A partir das SDs acima destacadas, pode-se depreender que, para a publicação em tela, a Argentina representa uma das grandes razões para o insucesso do bloco. 0 país é retratado como "cada vez mais protecionista" (SD30) e "agressivo" (SD33), dificultando as negociações e criando "obstáculos ao funcionamento do próprio Mercosul" (SD30). 0 jornal dá a entender ainda que o governo argentino ataca, particularmente, o Brasil (SD31), "arrancando [dele] mais vantagens" (SD31), através de "fórmulas calculadas para dispensar aquele sócio [o Brasil] de se tornar competitivo".

Ao final do Editorial 02, "Pobreza de ideias", o jornal desqualifica o governo argentino, reforçando sua posição ao indagar o motivo pelo qual os europeus continuam a tentar um acordo com "essa gente".

Em suma, a representação de determinados atores sociais (enfatizando qualidades ou defeitos) elaborada pelo jornal acaba revelando a perspectiva do enunciador e os interesses por ele defendidos. De acordo com Pêcheux (1997, p. 160),

O sentido de uma palavra, de uma expressão, de uma proposição, etc., não existe 'em si mesmo' (isto é, em sua relação transparente com a literalidade do significante), mas, ao contrário, é determinado pelas posições ideológicas que estão em jogo no processo sócio-histórico, no qual são produzidas (isto é, reproduzidas).

Assim, ao desconsiderar informações como, por exemplo, o fato de que a balança comercial brasileira tem se mostrado superavitária quando consideradas as transações 
comerciais com os países do Mercosul5, o jornal acaba colocando em segundo plano informações fundamentais que permitiriam ao leitor ter acesso a um quadro mais amplo, o que daria a oportunidade para que fosse formulada uma interpretação particular sobre as vantagens e desvantagens do bloco.

\subsection{FD4: a Venezuela antidemocrática}

Com duração de 14 anos, o governo Chávez foi frequentemente entendido como antidemocrático na opinião de autores a exemplo de Bijos e Cavalcante (2013, p. 10), apesar da realização de eleições periódicas na Venezuela. Ao se dedicar a essa temática em seus editoriais, OESP reitera sua rejeição à entrada de tal país no Mercosul.

Quadro 5 - Sequências discursivas relacionadas ao regime político venezuelano em interface com o Mercosul

\begin{tabular}{|c|c|}
\hline Sequência discursiva & Editorial \\
\hline $\begin{array}{l}\text { SD36: "[Marco Aurélio] Garcia esteve com os seus bons amigos Raúl e } \\
\text { Fidel Castro, além de se reunir com o vice chavista Nicolás Maduro, } \\
\text { príncipe regente e herdeiro designado da autocracia bolivariana." }\end{array}$ & \multirow{2}{*}{$\begin{array}{l}\text { E01: O Brasil no jogo } \\
\text { chavista }\end{array}$} \\
\hline $\begin{array}{l}\text { SD37: “Decerto também deve ter transmitido aos interlocutores a } \\
\text { garantia da presidente [Rousseff] de que apoiará seja lá o que os chavistas } \\
\text { e os seus mentores cubanos decidirem - ainda que atropelando a } \\
\text { Constituição criada pelo próprio regime...” }\end{array}$ & \\
\hline $\begin{array}{l}\text { SD38: "Hugo Chávez reencarnou num passarinho. A notícia foi dada } \\
\text { pelo sucessor do caudilho venezuelano, o presidente postiço Nicolás } \\
\text { Maduro... [...] Maduro, claro, assoviou de volta, porque, entre outras } \\
\text { qualidades fantásticas, ele entende a linguagem dos bichos, e } \\
\text { percebeu que se tratava de Chávez emplumado. }\end{array}$ & $\begin{array}{l}\text { E05: Chávez, o } \\
\text { passarinho }\end{array}$ \\
\hline $\begin{array}{l}\text { SD39: "Não se trata, pois, da eleição de um presidente, mas da unção do } \\
\text { filho de Deus na Venezuela - e, nesse caso, seu opositor, Henrique } \\
\text { Capriles, só pode ser o diabo." }\end{array}$ & \multirow{4}{*}{$\begin{array}{l}\text { E05: Chávez, o } \\
\text { passarinho }\end{array}$} \\
\hline $\begin{array}{l}\text { SD40: “A beatificação do falecido, como se sabe, começou logo depois de } \\
\text { sua morte, mas, à medida que o tempo passa, os hagiógrafos estão } \\
\text { perdendo qualquer pudor. }\end{array}$ & \\
\hline $\begin{array}{l}\text { SD41: "Como entidade divina, portanto, Chávez é onipresente, e as leis } \\
\text { terrenas não se aplicam a seus apóstolos." }\end{array}$ & \\
\hline $\begin{array}{l}\text { SD42: "Se havia necessidade de alguma prova adicional de que há na } \\
\text { Venezuela de hoje uma brutal regressão da democracia, a despeito do } \\
\text { que pensam os simpatizantes do chavismo no governo brasileiro, agora } \\
\text { não há mais." }\end{array}$ & \\
\hline
\end{tabular}

${ }^{5}$ De acordo com o Governo brasileiro, o Brasil teve superávit maior que US\$ 6 bilhões no comércio exterior com os países do Mercosul (BRASIL, 2014b). 
SD43: "A presidente Dilma Rousseff estenderá hoje o tapete vermelho a Nicolás Maduro, conferindo-lhe uma legitimidade que o presidente venezuelano está muito longe de desfrutar em seu próprio país."

SD44: "A oposição acusa os chavistas de fraudar a votação, de intimidar eleitores e de usar a máquina administrativa de forma irrestrita em favor do candidato governista, entre outras irregularidades."

SD45: "Ao mesmo tempo, Maduro e sua truculenta militância vêm empreendendo uma sistemática campanha para destruir a oposição, dona de metade dos votos na última eleição. [...] os chavistas agora impuseram limites à circulação de jornalistas na Assembleia Nacional."

SD46: "Pois é esse 'democrata' que será abraçado por Dilma, de quem receberá o apoio público e incondicional, mesmo diante de tantas arbitrariedades."

SD47: "Como se sabe, Maduro veio ao Brasil para obter a legitimidade política que lhe falta na Venezuela, graças à truculência com que ele está tratando a oposição."

SD48: "Tudo isso acontece em meio a uma avassaladora crise econômica, cujo lado mais perverso e politicamente explosivo é o desabastecimento de alimentos - que Maduro atribuiu à 'sabotagem econômica', sem reconhecer a óbvia incompetência de seu governo."

E09: Em busca de legitimidade

Fonte: Elaborado pelos autores.

A partir da leitura das sequências discursivas acima, verifica-se que o Estadão não perde oportunidade para criticar o governo venezuelano. Ao afirmar, na SD36, que o então vice-presidente Nicolás Maduro seria o "príncipe regente e herdeiro designado da autocracia bolivariana", o jornal equipara o modelo de governo venezuelano então vigente a uma monarquia. Na sentença, percebe-se o uso da hipérbole, figura de linguagem que, dentre outras tarefas, como reforçar a ironia, constitui um recurso de persuasão.

Mas é na SD38 que o jornal deixa transparecer mais fortemente seu desagrado por Maduro. Ao repetir a história, contada pelo então presidenciável, de que Chávez teria aparecido para ele em forma de um "passarinho", OESP ironiza a situação, de forma a ressaltar a improbabilidade do relato.

A campanha eleitoral teria sido marcada, conforme o periódico, pela "beatificação" (SD40) de Chávez. 0 jornal chega a afirmar que não se trata da eleição de um presidente, mas da "unção do filho [Maduro] de Deus [Chávez] na Venezuela". Com o triunfo de Maduro, o periódico passa a questionar a validade do resultado das eleições, conforme percebido na SD44. Um mês após o início da nova administração naquele país, o Estadão continua a atacar 
o presidente venezuelano, afirmando que Maduro revelou-se "incapaz" solução para enfrentar uma "avassaladora" (SD48) crise econômica.

Diante do panorama venezuelano delimitado pelo jornal, o Brasil é acusado de apoiar a qualquer custo o regime, considerado antidemocrático (SD37, SD43, SD46, SD47), conferindo a Maduro uma legitimidade que, segundo o jornal, ele não possui em sua própria nação (SD43, SD47).

\subsection{FD5: a suspensão do Paraguai}

No final de junho de 2012, dois episódios simultâneos afetaram a dinâmica de funcionamento do Mercosul: a suspensão temporária do Paraguai e a entrada da Venezuela no bloco. 0 processo conjunto de saída do Paraguai e de entrada da Venezuela no Mercosul é caracterizado pelo jornal como "golpe" (SD53 e SD54). Para OESP, a expulsão do Paraguai foi uma "decisão calculada" para "permitir o ingresso da Venezuela" (SD50, SD51) no bloco pela "porta dos fundos" (SD54).

Quadro 6 - Sequências discursivas relacionadas à suspensão do Paraguai do Mercosul

\begin{tabular}{|c|c|}
\hline Sequência discursiva & Editorial \\
\hline $\begin{array}{l}\text { SD49: "Ano passado, [Dilma] excluiu o Paraguai do Mercosul porque o colega } \\
\text { Fernando Lugo foi destituído pelo Congresso... [...] Mas, na Venezuela, o chavismo } \\
\text { fará o que bem entender com a Constituição... [...] - e não será Dilma quem } \\
\text { objetará." }\end{array}$ & $\begin{array}{l}\text { E01: O Brasil } \\
\text { no jogo } \\
\text { chavista }\end{array}$ \\
\hline $\begin{array}{l}\text { SD50: "Numa decisão calculada para permitir o ingresso da Venezuela de Hugo } \\
\text { Chávez no Mercosul, a que o Paraguai se opunha ferrenhamente, o país foi } \\
\text { suspenso do bloco..." }\end{array}$ & $\begin{array}{l}\text { E07: A volta } \\
\text { dos colorados }\end{array}$ \\
\hline $\begin{array}{l}\text { SD51: "É por isso que Maduro parece muito à vontade entre seus pares } \\
\text { bolivarianos no Mercosul, tão à vontade que, no auge do cinismo, se declarou } \\
\text { favorável à volta do Paraguai ao bloco..." }\end{array}$ & $\begin{array}{l}\text { E09: Em } \\
\text { busca de } \\
\text { legitimidade }\end{array}$ \\
\hline $\begin{array}{l}\text { SD52: "Restou a Dilma fazer um discurso curto, protocolar, em que exaltou a } \\
\text { 'parceria estratégica' entre Brasil e Venezuela..." }\end{array}$ & $\begin{array}{l}\text { E11: Chá de } \\
\text { cadeira em } \\
\text { Dilma }\end{array}$ \\
\hline $\begin{array}{l}\text { SD53: "No caso do Paraguai, esse descontentamento [com o MERCOSUL] é } \\
\text { reforçado pelo tratamento imposto ao país depois da cassação do mandato do } \\
\text { presidente Lugo. Esse tratamento foi parte de um golpe para facilitar a } \\
\text { admissão da Venezuela bolivariana, uma democracia exemplar, segundo os } \\
\text { governos petista e kirchnerista." }\end{array}$ & $\begin{array}{l}\text { E12: } 0 \\
\text { mundo } \\
\text { negocia sem o } \\
\text { Brasil }\end{array}$ \\
\hline $\begin{array}{l}\text { SD54: “[trecho de estudo da Fiesp] 'Não apenas as regras do Mercosul são } \\
\text { suficientemente flexíveis para acomodar as prioridades dos membros [...] como } \\
\text { há formas construtivas para acomodar as circunstâncias individuais de cada } \\
\text { Estado.' Mais que discutível, essa frase parece uma confissão: a Fiesp considera } \\
\text { um exemplo de flexibilidade o golpe vibrado contra o Paraguai para que se } \\
\text { pudesse admitir a Venezuela pela porta dos fundos? }\end{array}$ & $\begin{array}{l}\text { E15: Uma } \\
\text { Fiesp } \\
\text { bolivariana? }\end{array}$ \\
\hline
\end{tabular}

Fonte: Elaborado pelos autores. 
No contexto, o jornal ainda retrata Dilma Rousseff como inconstante, ao "excluir" (SD49) o Paraguai do Mercosul e não objetar que os Chavistas façam "o que bem entenderem com a Constituição" (SD49), sugerindo dubiedade de posicionamento da presidente brasileira. 0 periódico ainda aproveita para desqualificar os governos petista e kirchnerista ao afirmar que, para ambos, a Venezuela seria uma "democracia exemplar" (SD53). Em suma, o jornal defende que a suspensão do Paraguai foi um artifício planejado pelos outros membros do bloco para facilitar a entrada da Venezuela, contribuindo para a desqualificação do bloco.

Quando boa parte dos editoriais caracteriza o presidente Nicolás Maduro como incompetente ou truculento, o jornal apresenta suas visões de mundo (reforçando o compromisso que assumiu com o leitor por meio do que está publicado no documento Código de Conduta e Ética, apresentado anteriormente), ao mesmo tempo em que demanda de seus leitores uma compreensão prévia sobre o que tais termos significam do ponto de vista político-histórico.

O jornal OESP, quando se define defensor da "liberdade", por exemplo, reivindica para si um posicionamento expresso por meio do uso da língua, construindo, ao mesmo tempo, um princípio ideológico e uma relação (que pode ser de aproximação ou de afastamento, caso a audiência discorde) com o leitor. No caso, o editorial constrói um tipo de contrato singular, na medida em que o texto opinativo não necessariamente clama pela objetividade e pela imparcialidade, o que localiza o material em outro tipo de projeto discursivo.

A este ponto, já é possível retomar a discussão proposta por Steinberger (2005b, p. 24), para quem a comunicação de massa "[...] tem hoje o poder de configurar mentalidades e, portanto, [pode angariar] o apoio necessário à consolidação do projeto de qualquer liderança internacional [...]". Em outras palavras, as transações entre os países e a imagem de líderes nacionais acabam sendo influenciadas pelos "modos de apresentação do mundo" propiciados pela comunicação de massa (especialmente, pelo Jornalismo) (STEINBERGER, 2005b p. 184). 0 mesmo ocorre quando determinadas visões são oferecidas como a única alternativa, em detrimento de outras, o que diminui a possibilidade de que discursos hegemônicos sejam contestados. É o caso dos modos através dos quais OESP caracteriza os vizinhos brasileiros, sentindo-se mais à vontade para criticá-los em espaço dedicado exclusivamente à opinião da empresa. 
Restringir-se à opinião do periódico faz, então, com que o leitor acabe rejeitando ou nem mesmo tendo a oportunidade de conhecer outras perspectivas - descarta-se, por exemplo, o fato de que o Brasil poderia se tornar referência para países em desenvolvimento, legitimando-se em outros fóruns de interesse para a diplomacia nacional. A ideia de ganho promovida pelo jornal $O$ Estado de $S$. Paulo enfatiza o lucro na esfera econômica, deixando de lado o prestígio político que pode ser tão importante quanto à geração de riquezas.

\section{Para concluir}

Charaudeau (2010) destaca, dentre as tarefas da comunicação de massa, a função de reguladora do cotidiano social, influenciando o que é percebido coletivamente como algo que merece aprovação ou reprovação. Mas o que dizer quando se lida com gêneros de opinião no Jornalismo? Que diferenças do ponto de vista da construção ideológica do discurso podem ser percebidas?

A fim de colaborar na reflexão sobre tais questões, a pesquisa teve como finalidade analisar o posicionamento editorial do jornal O Estado de S. Paulo acerca do Mercosul. Conforme Melo (2003), embora os editoriais se dirijam formalmente à opinião pública, parte de sua função consiste em dialogar diretamente com os agentes representativos do estado, sinalizando como a empresa jornalística entende que os assuntos públicos devem ser orientados. Esse comportamento é visível no caso de OESP, que, frequentemente, sugere medidas e ações divergentes daquelas adotadas pelo governo.

Verificou-se que o Mercosul é retratado pelo periódico de forma regularmente negativa, corroborando-se a hipótese da investigação, o que tem o potencial de despertar no leitor um sentimento de descrença em relação ao futuro ou aos ganhos advindos a partir das negociações realizadas no âmbito do bloco. As figuras de linguagem presentes no material, como a ironia, o sarcasmo e a hipérbole, estabelecem com o leitor uma relação de cumplicidade interpretativa (BENETTI, 2008), tentando induzi-lo a concordar com o discurso do jornal.

Na primeira FD identificada, o bloco é percebido como um entrave ao Brasil e apontado como uma das razões pelas quais o país não conseguiria obter melhor êxito econômico. A política externa brasileira e a gestão petista, particularmente, são retratadas na segunda FD como grandes culpados pela frágil posição do Brasil perante o comércio internacional - o governo é caracterizado como detentor de ideais pouco pragmáticos do 
ponto de vista do comércio. A terceira FD, ao construir a imagem da Argentina como protecionista e problemática, aponta-a como uma das principais culpadas pela crise do bloco econômico. A Venezuela, na quarta FD, é retratada como um país antidemocrático e em grave crise econômica, o que a tornaria um parceiro comercial e político desinteressante. A quinta FD, que diz a respeito à questão da suspensão do Paraguai e da entrada da Venezuela do bloco, é mais um argumento cuja interpretação reforça a perspectiva do jornal de que o Mercosul seria irrelevante no cenário mundial.

É verdade que nem todos os analistas concordam com o diagnóstico de que o bloco tem fracassado em suas tentativas de integração (BATISTA JR., 2008). 0 jornal, por outro lado, assume uma postura incisiva em seus editoriais e, com isso, esforça-se para persuadir os leitores a perceberem a realidade de acordo com o quadro que ele constrói (SOUZA, 2006).

\section{Referências}

ALBUQUERQUE, A. Um outro quarto poder: jornalismo e responsabilidade política no Brasil. Contracampo, Rio de Janeiro, v. 4, p. 23-57, 2000.

ALMEIDA, P. R. O Brasil e os blocos regionais: soberania e interdependência. São Paulo em Perspectiva, São Paulo, v. 16, n. 1, p. 3-16, 2002.

ASSOCIAÇÃO NACIONAL DE JORNAIS. Maiores jornais do Brasil. Brasília, 2014. Disponível em: <http://goo.gl/Tq6hAu>. Acesso em: 19 ago. 2016.

BATISTA JR., P. N. A América do Sul em movimento. Revista de Economia Política, São Paulo, v. 28, n. 2, p. 226-238, 2008.

BELTRÃO, L. Jornalismo opinativo. Porto Alegre: Sulina, 1980.

BENETTI, M. Análise do discurso em jornalismo: estudo de vozes e sentidos. In: LAGO, C.; BENETTI, M. (Org). Metodologia de pesquisa em jornalismo. Petrópolis: Vozes, 2008.

BERNAL-MEZA, R. Argentina y Brasil en la política internacional: regionalismo y Mercosur (estrategias, cooperación y factores de tensión). Revista Brasileira de Política Internacional, Brasília, v. 51, n.2, p. 154-178, 2008.

BIJOS, L.; CAVALCANTE, D. O. Reflexões a respeito da entrada da Venezuela no Mercosul. In: JORNADAS DE LA ASOCIACIÓN ARGENTINA DE HISTORIA DE LAS RELACIONES INTERNACIONALES, 14., 2013, Buenos Aires. Anales... 2013.

BRASIL. Ministério da Educação. Conselho Nacional de Educação. Câmara de Educação Superior. Resolução no 1, de 27 de setembro de 2013. Institui as Diretrizes Curriculares 
Nacionais para o curso de graduação em Jornalismo, bacharelado, e dá outras providências. Diário Oficial da União, Brasília, DF, p. 26, out. 2013. Disponível em: <http://goo.gl/77l7Ee>. Acesso em: 21 ago. 2016.

BRASIL. MERCOSUL. Saiba mais sobre o Mercosul. [Brasília, 2014a]. Disponível em: <http://www.mercosul.gov.br/saiba-mais-sobre-o-mercosul>. Acesso em: 19 ago. 2016.

BRASIL. Portal Brasil. Brasil terá superávit superior a US\$ 6 bilhões em 2014. [Brasília]: 2014b. Disponível em: <http://goo.gl/fa4eEQ>. Acesso em 25 ago. 2016.

CAMARGO, L. H. K.; GABIATTI, D. A.; MELLO, R. T. O processo de impeachment do expresidente paraguaio Fernando Lugo: observando o fenômeno jurídico material à luz da teoria crítica do direito. Unoesc \& Ciência, Joaçaba, v. 3, n. 2, p. 157-170, 2012.

CAMPOS, C. L. O. Estratégias de referenciação no discurso midiático: práticas ideológicas de inclusão e exclusão de dizeres no discurso sobre a guerra. Linguagem em (Dis)curso. Palhoça, v. 10, n. 1, p. 43-67, 2010.

CAPELLE, M. C. A.; MELO, M. C. O. L.; GONÇALVES, C. A. Análise de conteúdo e análise de discurso nas ciências sociais. Organizações Rurais \& Agroindustriais, Lavras, v. 5, n. 1, 2003.

CELLI JUNIOR, U. Teoria geral da integração. In: MERCADANTE, A. de A.; CELLI JUNIOR, U.; ARAÚJO, L. R. de (Coord.). Blocos econômicos e integração na América Latina, África e Ásia. Curitiba: Juruá, 2006. p. 19-37.

CHAGAS, V. Papel de embrulhar peixe: uma análise sobre o modelo econômico de distribuição dos jornais e seus prognósticos. Contemporanea, Salvador, v. 12, p. 410-427, 2014.

CHARAUDEAU, P. Discurso das mídias. São Paulo: Contexto, 2010.

COOK, T. E. Governing with the news. Chicago: The University of Chicago Press, 2005.

ENTMAN, R. M. Projections of power: framing news, public opinion, and U.S. foreign policy. Chicago: University of Chicago Press, 2004.

ESTADÃO. 2016. Disponível em: <www.estadao.com.br>. Acesso em: 19 ago. 2016.

FOLETTO, R. De bispo a presidente: construções histórico-midiáticas do presidente paraguaio Fernando Lugo nas revistas semanais brasileiras. Estudos em Comunicação, Covilhã, n. 10, p. 227-243, 2011.

FOLHA ONLINE. Brasil investe no Mercosul para não ficar com o "osso" da Alca. [2001]. Disponível em: <http://goo.gl/N81dSs>. Acesso em: 19 ago. 2016.

GALTUNG, J.; RUGE, M. H. The structure of foreign news. Journal of Peace Research, v. 2, n. 1, p. 64-90, 1965. 
GEHRE, T. "Dança das cadeiras no Mercosul”: uma avaliação crítica. Boletim Meridiano 47, Brasília, v. 13, n. 133, p. 47-53, set./out. 2012.

GOMES, W. Transformações da política na era da comunicação de massa. São Paulo: Paulus, 2004.

GRUPO ESTADO. Código de conduta e ética. [2016]. Disponível em: <http://www.estadao.com.br/ext/codigoetica/codigo_de_etica_miolo.pdf >. Acesso em: 19 ago. 2016.

LISBOA, S. S. M. Jornalismo e a credibilidade percebida pelo leitor: independência, imparcialidade, honestidade, objetividade e coerência. 2012. Dissertação (Mestrado em Comunicação e Informação) - Universidade Federal do Rio Grande do Sul, Porto Alegre, 2012.

MACADAR, B. M. B. As relações comerciais Brasil-Argentina: evolução recente. Indicadores econômicos FEE, Porto Alegre, v. 37, n. 2, 2009.

MANHÃES, E. Análise do discurso. In: DUARTE, J.; BARROS, A. (Org.). Métodos e técnicas de pesquisa em comunicação. 2. ed. São Paulo: Atlas, 2010.

MARQUES, F. P. J. A.; MIOLA, E.; SIEBRA, N. Jornalismo, assessoria de imprensa e seus condicionantes organizacionais: uma reflexão a partir das teorias do jornalismo. Animus, Santa Maria, v. 13, p. 145-166, 2014.

MAYRINK, J. M. Uma vida de 136 anos e cada vez mais novo. 0 Estado de S. Paulo, 04 jan. 2011. Disponível em: <http://goo.gl/GqB8i2>. Acesso em: 19 ago. 2016.

MAZIÈRE, F. A análise do discurso: história e práticas. São Paulo: Parábola Editorial, 2007.

MELO, J. M. de. Jornalismo opinativo: gêneros opinativos no jornalismo brasileiro. 3. ed. Campos de Jordão: Editora Mantiqueira, 2003.

MONT'ALVERNE, C.; MARQUES, F. P. J. A. A opinião da empresa no jornalismo brasileiro: um estudo sobre a função e a influência política dos editoriais. Estudos em jornalismo e mídia, Florianópolis, v. 12, p. 121-137, 2015.

PALACIOS, A.; VILLAVERDE, J. Presidente eleito do Paraguai rejeita voltar a Mercosul liderado por Caracas. 0 Estado de S. Paulo, 12 jul. 2013. Disponível em:

$<$ http://internacional.estadao.com.br/noticias/geral,presidente-eleito-do-paraguai-rejeitavoltar-a-mercosul-liderado-por-caracas,1052922>. Acesso em 16 ago. 2016.

PÊCHEUX, M. Semântica e discurso. Campinas: Ed. Unicamp, 1997.

PÊCHEUX, M. Remontémonos de Foucault a Spinoza. In: TOLEDO, M. M. (Org.). El discurso político. Cidade do México: Universidad Nacional Autónoma de México, Editorial Nueva Imagem, 1980.

PENA, F. Teoria do jornalismo. 2. ed. São Paulo: Contexto, 2010. 
PROTOCOLO de Ushuaia sobre Compromisso Democrático no Mercosul, Bolívia e Chile. 24 de julho de 1998. Disponível em:

<http://www.mercosur.int/innovaportal/file/110/1/1998_protocolo_de_ushuaiacompromiso_democratico_port.pdf>. Acesso em: 19 ago. 2016.

RITTNER, D. Mercosul revoga suspensão ao Paraguai. Valor Econômico, 12 jul. 2013. Disponível em: <http://goo.gl/ccbN33>. Acesso em: 19 ago. 2016.

RODRIGUES, T. S. F.; PAULA, N. M. de. A agricultura nas negociações multilaterais da Rodada Doha e suas implicações para o Brasil. Revista de Economia, Curitiba, v. 34, n. 2, p. 95-115, mai./ago. 2008.

SCHEMBIDA, R. E. Las bases de la inestabilidad: cultura e instituciones políticas en Paraguay. Revista Paraguay desde las ciencias sociales, Buenos Aires, n. 1, p.149-172, 2012.

SCHUDSON, M. Why democracies need an unlovable press. Cambridge: Polity, 2008.

SILVA, M. A.; JOHNSON, G. A.; ARCE, A. M. O Mercosul em seu labirinto: desafios da Integração Regional. Revista de Geopolítica, Natal, v. 4, n. 1, p. 52-64, jan./jun. 2013.

SILVEIRA, M. C. O Jornalismo como usina de preconceito: a propagação de estereótipos nos países do Mercosul e o caso paraguaio. Revista latinoamericana de ciencias de la comunicación, São Paulo, v. 2, p. 32-43, 2005.

SOARES, G. A. D. A América Latina na imprensa brasileira. Opinião Pública, Campinas, v.10, n.1, p. 63-90, 2004.

SOUSA, L. S. C. Mercosul, sociedade e opinião: exercícios de hegemonia na página de opinião da Folha de S. Paulo. Carta Internacional, São Paulo, v. 3, n. 3, p.17-22, out. 2008.

SOUTO MAIOR, L. A. P. O Brasil e o regionalismo continental frente a uma ordem mundial em transição. Revista brasileira de política internacional, Brasília, v. 49, n. 2, 2006.

SOUZA, M. M. Transitividade e construção de sentido no gênero editorial. 2006. Tese (Doutorado em Letras) - Universidade Federal de Pernambuco, Recife, 2006.

STEINBERGER, M. B. Jornalismo e imaginário internacional sobre o Mercosul. Estudos em jornalismo e mídia, Florianópolis, v. 2, n. 2, p. 63-73, 2005 a.

STEINBERGER, M. B. Discursos geopolíticos da mídia: jornalismo e imaginário internacional na América Latina. São Paulo: Cortez, 2005b.

STURARO, G. W.; FROTA, A. F. M. A suspensão do Paraguai e a entrada da Venezuela: implicações para o regime de defesa coletiva da democracia no Mercosul. Revista Conjuntura Austral, Porto Alegre, v. 3, n. 13, p. 45-53, ago./set. 2012. 
TERUCHKIN, S. U. Ampliação do Mercosul: a adesão da Venezuela. Indicadores Econômicos FEE, Porto Alegre, v. 34, n. 3, p. 45-50, dez. 2006.

TRAQUINA, N. Teorias do Jornalismo: por que as notícias são como são. Florianópolis: Insular, 2005.

TUCHMAN, G. Objectivity as strategic ritual: an examination of newsmen's notions of objectivity. The American Journal of Sociology, [S.l.], v. 77, n. 4, p. 660-679, 1972.

VIGEVANI, T.; MARIANO, M. P.; MENDES, R. G. Instituições e conflitos comerciais no Mercosul. São Paulo em perspectiva, São Paulo, v. 16, n. 1, p. 44-53, 2002.

WEBER, R. P. Basic content analysis. Newbury Park: Sage University Papers, 1990.

\title{
The world turns around without MERCOSUR:
}

\section{A study on the $O$ Estado de S. Paulo's}

\section{editorials}

\begin{abstract}
This research aims to analyze the discourse of the O Estado de S. Paulo's editorials in order to examine how they frame Mercosur. Our sample took into account 16 editorials published between January and June of the year 2013. The article presents the following hypothesis: Once its editorial principles defend the idea of free market, OESP cultivates a negative image of Mercosur. By using Discourse Analysis, we identified five discursive formations regarding the performance of diplomatic agents and the advantages and disadvantages that political and economic integration have brought to Brazil according to the newspaper's view: (1) the Mercosur's burdens; (2) an alleged passivity of the Brazilian government before its neighbors; (3) the Argentina's protectionism; (4) the anti-democratic Venezuela; 5) the suspension of Paraguay as a "coup". We conclude that the newspaper's opinion tends to disqualify the Mercosur, framing it as a failed economic strategy. Through the editorials, O Estado de S. Paulo tries to build a unique kind of relationship with its readers by supporting an ideology of economic freedom.
\end{abstract}

\section{Keywords}

Mercosur. Editorial. Journalism. Foreign affairs. Opinion.

Recebido 02/09/2016

Aceito $19 / 04 / 2017$ 